\title{
The Performance of Project Teams Selected Based on Student Personality Types: A Longitudinal Study
}

\author{
Svitlana Ivanova ${ }^{1}$, Lubomir Dimitrov $^{2}$, Viktor Ivanov $^{*}, 3$, Galyna Naleva ${ }^{4}$ \\ ${ }^{1}$ South Ukrainian National Pedagogical University named after K.D. Ushynsky, Department Mathematics and its teaching methods, \\ Odesa, 65020, Ukraine
}

${ }^{2}$ Technical University of Sofia, Department Mechanical Engineering, Sofia, 1000, Bulgaria

${ }^{3}$ Odessa National Polytechnic University, Department Mechanical Engineering and elements of machine, Odesa, 65044, Ukraine

${ }^{4}$ Ukraine National University “Odesa Maritime Academy”, Department of Higher Mathematics, Odesa, 65029, Ukraine

A R T I C L E I N F O

Article history:

Received: 28 November, 2020

Accepted: 05 February, 2021

Online: 25 February, 2021

Keywords:

Project Method

Heuristic Method

Personality Types

\begin{abstract}
A B S T R A C T
The use of heuristic methods in teaching is not possible without the cooperation of all or part of the students' academic group. That is, the teacher who made the decision to apply the heuristic method de facto solves the issues of organizing project method in teaching. There are a large number of indications on the relationship between the effectiveness of the use of heuristic methods, taking into account the personality differences of students. As well as the importance of taking into account the personality differences in the project method. However, there is a lack of information about experimental studies in which three components: the project method, the heuristic method and the Myers Briggs personality types methodology, would be considered simultaneously. This prompted us to conduct this study. As part of the project method, a tournament among students of prospective mathematics teachers was held during 2014-2020. Teams of three types to participate in the competition were formed. There was a team whose members were not previously trained. The team whose members studied the heuristic method - "Creativity enhancement method". And also a team whose members, along with the study of the heuristic method, were selected in a special way. Students included in this group had personality types most suitable for performing heuristic techniques, which are components of the heuristic method. The task of the tournament was to compile a set of educational problems in geometry that can be used in the school curriculum. The problems developed by the team were evaluated by the panel. Members of other teams acted as opponents and reviewers. Using the heuristic method allowed teams to prepare more problems and systematize them. The best results in the use of the heuristic method showed the team, the composition of which was selected in a special way. The survey conducted according to the results of the tournament showed an increase in students' interest both in the studied discipline and in the project method, as well as a willingness to use the project method in their future work.
\end{abstract}

\section{Literature review}

\subsection{Problem-based learning}

The experiment on the application of the project method in the study of the discipline "Mathematics training methodology" was carried out from 2014 to 2020 year. This article is a generalization and continuation of the work originally presented at the
International Conference on High Technologies for Sustainable Development, which describes the 2014-2018 experiment [1].

Problem-based learning (PBL) is a widely spread teaching method. This method has the following features: using collaboratively work in groups or teams, using principle "learning by doing", increased motivation and interest in learning outcomes [2]. 
Creative techniques are also used [2]. In its turn, principle "learning by doing" include such techniques: learning by trial and error, evidence in practice, experience versus book learning, discovery versus instruction [3]. Another point of view on the main features of PBL in [4] is as follows: the method involves solving a problem posed by the student, initiative of a group of students by the form of study, results of research and activities in the form of the final product, long-term project, and teachers are used only as consultants. The PBL is considered as three principal approaches: learning, contents and social [5]. The term learning means cognitive learning, which have follows peculiarities: the problem is focused on learning, learning versus experiment, enhancement motivation and study within the framework of the project. These peculiarities are the same that point out above. The content approach first of all implies interdisciplinary learning. The social approach is mean that student organize in project team and get project management skills.

At all source mentioned above indicate such features of PBL; cognitive character of learning (including heuristic methods [5]); student should be organized in group; the goal is to solve the problem (this solution to the problem is carried out within the framework of the project $[4,5])$. One author is using term a group [4], another is using both term group and team [2]. It is more clearly stated in [5] - the project team is working on the project. Direct link to project management is here.

\subsection{Elements of role-playing projects in $P B L$}

In this and other publications, the project method is equated to PBL. But, according to [6], there are four types of projects: construction, enjoyment, problem and specific learning. Thus PBL is only a third type of project. The "construction" project constructs the interaction of the project team members according to certain circumstances. This means that role projects, as well as their wellknown variety - a business game - are construction projects. We believe that all types of projects include elements of construction project and PBL. When considering PBL projects, at least the role of the teacher and the role of the team leader are highlighted. Also, the size of the team is usually taken into account.

In [2] the team contract is considered to be an interesting PBL tool. This contract contains the project rules namely: objective of the project, communication between team members, rules and procedures for meetings, etc. At this contract experience of project method is used. As example, a resource and time management elements are include. The team role distribution is considered at item - define the responsibilities of each team member. The role of the teacher is described as a facilitator of the learning process in [2]. Group size guidelines are given. Students which study engineering in framework of PBL perform project tasks in industry. The teacher acted as a mediator among the student group and employees of the firm. The number of assistant lecturers should be limited [7].

In the case of real project, special employee of the company an instructor can be assigned. He selects a project topic, prepares the presentation of the project for a group of students with a statement of the problem and meets regularly with the members of the group [7]. But inspector should not execute the project instead of students or impose their opinion on them. It is also considered necessary to have an instructor who must prepare important data and organize information for students [2]. The instructor ensures a link between educational tasks with real problems. Another problem is that the use of the project method to solve real problems presupposes the existence of a core of good academic standing and conscientious students. Lack such of core creates an incredible administrative struggle to compensate for lack of student's motivation and to maintain the quality of the final product for the client [7]. Also, the potential problem for the implementation of real projects should be limited in scope so that the task does not exceed academic terms - a quarter or a semester.

In [8] example of student's group from 5 to 45 is provided. But note that more often groups of 5-7 are applied. It is point out that two faculty advisers should provide the work of student's group [8]. In [9] teaching roles in problem-based learning is described as a process-oriented supervisor.

PBL uses the results of research in the field of cognitive psychology to enhance creativity and increase interest [10]. The size of group is considered; note that for most purposes 3-5 members feasible is recommended. But this recommendation is not based on scientific analysis, but only on experience. Regarding the long-term project, it is indicated that most of the project terms are four years, when the whole process of studying at the university is performed on one project [10]. It should be noted that the work of the project team is provided by one or two teachers [10].

\subsection{The role of teacher}

The role of teachers is advisory, rather than authoritarian. Teachers used teaching assistant as mentors. On a final stage the report to the client is prepared with help a research assistant [10]. In [11] it was concluded that the group size and team tenure don't influence at the team performance. Note that both the term group and command are used in [10] and [11].

At the each publication mention above the role of a teacher is discussed. In detail the teacher's role is investigated in [12]. This role changes according to stage of a project. At the preparatory stage, the teacher motivates the students, helps in setting the goals of the project. When performing the main stage teacher directs the process. At the final stage the teacher is involved in summarizing works as an independent expert [12]. There are notes that it is very difficult for a teacher to plan or execute projects with students and control them at the same time. In [10] for decided this problem the senior seminar students as mentors are used. In order to avoid the monitoring problems, the teacher may assign a leader for each group of students. Collective execution of the project may lead to the fact that the poor academic standing students avoid academic work. Therefore, the teacher can use individual evaluations, along with a general evaluation of the performance of the group [7]. Such an evaluation can also be given by the instructor (research assistant) and each member of the group can evaluate the contribution of his colleagues during the various stages of the project [7]. In [13] identifies various ways of organizing the work of the teacher: with open (explicit) coordination or with hidden coordination (including the coordinator in the work on the project). In [14] refer different options for the distribution of roles between the teacher and students. In the case that the total amount of work can be divided into independent parts for each student, the role of the co-ordinator falls upon the teacher. In the case when it is possible to identify the main and auxiliary tasks, and also when the 
final distribution of tasks between students occurs in the process of performing assignments, the role of the co-ordinator falls upon the teacher and one of the students. Such a distribution of roles exists when performing of integrated master's theses when several students develop one topic [14].

The main sources mentioned above are connected project approach with creating a group. In [15] note that obviously, the group is fundamentally and, when possible, students should be grouped. It is important to give students time to study group behaviour and performance. A study of the work in the student group showed that although the teacher's intervention and management led to improved student satisfaction with the results of the project, this negatively affected group unity [15]. An interesting variant in which the function of the co-ordinator is entrust to one of the students. This student co-ordinator is usually chosen from among the most successful students [16]. In general, many researchers distribute students into "strong" and "week", meaning only their academic achievements. For election of coordinator, such a feature as a high sense of responsibility, can take into account, for example [15].

In [11] pays attention to the need to take into account the personal differences of students while monitoring their academic achievements. So, students in different ways can show themselves in oral or written evaluation. To take account of these differences is proposed to use socionics typology [17]. Refer that the project method is also assumed control of academic achievements. In [18] insists that the same teaching method gives different results for students with different personality types. He invited to divide students into small groups so that each group included representatives of only one personality types. [18].

\subsection{Student competition}

The foregoing article consider different aspect of project method at education; these are: increasing creativity, "learning by doing", increased motivation, results of research and activities in the form of the final product, teacher's role, size of group and selection team members in according there personality types. Depending on the type of project, this or that moment turns out to be very important. It is consider the projects, which included this entire item. These projects are based on student's competitions.

The Formula Student team includes from 40 to 50 members typically [19]. This large team is parted into sub-teams of 3 or 4 participants. A large project team has a leader called the captain. Usually this role is performed by a graduate student. The formalized roles are systems engineer and managers responsible for marketing and financial matters [19]. The captain and faculty member is controlled financial issues, also. An adviser and industry mentor supported each large team. In this case is realized problem learning study: team solve problem of automobile design with final product - racing car. As well role-playing project is realized. The students are performed role of design division of automobile company.

The same examples when there is a PBL project and a role project and also the final product are World Robot Olympiad and Robot Soccer World Cup. Another example is student tournaments. International Natural Sciences Tournament (INST) is including following specializations: Chemistry, Material Science,
Geography, and Engineering. University students can participate in the team. The researcher or doctoral student acts as a trainer. Separate tournaments in mathematics (International Tournament of Young Mathematicians) and physics (International Physicists' Tournament) are held.

The International Physicists' Tournament (IPT) has the most established and regulated rules for conducting [20]. The IPT preparatory work on the formation of tasks carried out group of teachers, which is then not in contact with students. The other teachers, usually four of them, are panel members. Each team has the adviser - PhD student. Team is headed by the captain; he is one of a student. Teams of six students receive a list of tasks that can be solved experimentally or theoretically. In a round of a tournament, each team plays one of the following roles: speaker, opponent, and reviewer. Each task consists of three rounds, i.e. each team must play all three roles. Along with the team competition, the participant's personal contribution is assessed. Speakers and Opponents who receive an above average grade for their performances receive personal points. Individual winners of the Tournament are determined by the total amount of personal points.

Point out that in a number of cases, the work result of the project team may be not only in obtaining certain knowledge and skills, but it have practical result. Practical result is important when:

- A project is real and results of which will be used in practice;

- Competition between projects groups, for example - Formula Student, IPT, INST, etc.;

- Business games, when the insufficient level of results breaks the plot of the game and does not allow achieving the necessary knowledge and skills;

- This is the study of heuristic methods, when the absence of a result will not allow to fully revealing the content of the topic.

\subsection{The results of the review and the objectives of the study}

The effectiveness of the application of project method, as reviewed by the literature sources, is related to the features of the formation and work of project teams. Recommendations for the size of the project team are very different - from 2 to 12 members. Note that there are usually 15-25 students in an academic group. The size of the project team depends on the size of the academic group, due to organizational factors. Conveniently if all students of an academic group are included in the project team or two teams are formed from this academic group. The most common recommendation is that the project team should be small, but for more teams, more teachers should be involved than a lecturer and assistant.

In two cases, it is important to distribute roles between students in the project team - in the implementation of long-term projects and in student team tournaments. Long-term projects can be implemented for execution of a bachelor's degree project, a master's degree project and a term paper formed to work for a long period of time. The project team can be formed for a year or more for implementing collaborative interdisciplinary or research projects. In [11], it was concluded that group size does not affect team performance. We assumed this was due to the fact that team members were selected without regard to their personal 
differences. Extensive experience in the formation and organization of project team interaction has been accumulated in project management. As a rule, the distribution of roles between students of the team members is spontaneous: someone is chosen for the role of leader, someone is a generator of ideas, and someone is responsible for processing the results of the work. Sometimes students themselves are called to perform certain functions in the team. However, there are various scientifically valid typologies of team roles. This distribution can be performed on the basis of the project management theory. The terminology accepted in project management, namely: project team, teamwork, team roles, is also expedient to use. The heuristic nature of the design method is often noted. The content of the project method can be the work of the team to study and apply the heuristic method [21]. In this case the distribution of team roles should be performed on the basis of personality type's methodologies [21]. The important question is about the role of the teacher in the project method. The roles of teachers vary. Teachers prepare material and project rules. They are advisers and evaluate students. Is teacher outside the project team or its member? Usually it depends on which project we are considering. In a short-term project, the teacher is out of the project. If the subject of the study is a long-term project, then the teacher can be an advisor and even be a member of the project team.

The study includes a preparatory stage, which consists of building project teams, teaching students to use the heuristic method and surveys to determine their personality type. The experiment itself included the organization of a tournament, work with the use of a heuristic method, including taking into account the personality type of students. As well as the panel's assessment of the teams' work results and a survey of the participants about the experiment results. At the analysis stage, the performance of the project teams, and the effectiveness of using individual techniques of the heuristic method by students with certain personality types were compared.

\section{The methodology of experiment}

\subsection{The hypothesis of the study}

The project method is widely used in education. The scientific basis of this method was developed in project management. The guidelines for team size and selection of team members were generally developed based on the team role methodology. Often the purpose of forming a project team is to ensure teamwork within the heuristic method. The methodology of personality types is more suitable for selecting group members and organizing the interaction of team members in the case when the application of the heuristic method is the reason for the formation of the project team. The lack of data on the combination of personality type's methodology, heuristic method and project method should make up for this experiment.

The following statement is accepted as hypotheses of a study:

- $H_{a}$ - The use of the heuristic method, allows to improve the performance of the team.

- $H_{b}$ - The formation of a project team, taking into account the personality types of students, allows to improve the performance of the team.
- $\quad H_{c}$ - The use of the project method in the form of team competition increases the interest of team members in the application of this method.

\subsection{Tools are used to test these hypotheses of a study}

The Keirsey Temperament Sorter. Student's personality types were determined using the Keirsey questionnaire [22]. The first test was conducted six months before the tournament. The second test was performed immediately before the tournament. Along with personality types, their brightness was determined. The test was carried out on the basis of an adapted version of the test in Ukrainian (http://ibib.ltd.ua/2211-test-keyrsi-tekst-35784.html). Two academic groups consisting of 15-20 students in each took part in testing. The coincidence of the results of the first and second tests was in the range of $76-81 \%$, which is within the acceptable range (75-90\%) in accordance with [23]. Students with personality types necessary for the execution of the heuristic method algorithm were selected to the first group. Of the students with the same personality types, preference was given to the participants with the brighter type.

The expert evaluation. The teacher and two $\mathrm{PhD}$ students prepared tasks for the tournament and became members of the panel. The panel members evaluate each problem based on a report and discussion. The maximum score is 100 points. The problem was evaluated on four items: correctness of composing and solving the problem (40), completeness of methodological recommendations (20), compliance with the requirements of the educational set of problems (20), consistency, clarity and validity of each stage in the presentation of the problem (20).The maximum number of points for each item is indicated in parentheses. The individual contribution of each participant was also assessed. The maximum score also is 100 points. The problem was evaluated on five items: ability to report, ability to debate, quickness in correcting your mistakes, finding mistakes in opponents, the ability to analyze the proposed sets of problems from a methodological point of view. The maximum score of each item is 20 points.

The survey. A survey was conducted following the experiment. All students answer the questions "Do you like the project method?" and "Will you use the project method in your future work?". The members of first and second team answer the questions "Do you like the heuristic method?" and "Will you use the heuristic method in your future work?". The members only of first team answer the questions "Do you like the distribution team role due personality type?" and "Will you use the distribution team role due personality type in your future work?".

\subsection{The heuristic method}

It was decided to use as a heuristic method "creativity enhancement method" [21]. This method included several heuristic techniques, namely: collective discussion, pause between the presentation of ideas and their criticism, random associations, analogy, expert evaluation, using a matrix. The sequence of heuristic techniques is follow. At first is applied three techniques collective discussion, pause between the presentation of ideas and their criticism, expert evaluation. This three techniques is represented a all known brainstorming. The main difference of a creativity enhancement method in contradistinction to another 
method based on brainstorming is using matrix. The purpose of the first three heuristics is to determine what sense should be given to the row and column. Second part of heuristic techniques follows. These are random associations, analogy and expert evaluation. The goal of techniques random associations and analogy is to generate ideas about the semantic content of the first row and first column elements. Expert evaluation technique is used to select better variant of ideas. Third part of heuristic techniques grouped around the matrix. These are using a matrix, collective discussion and expert evaluation. The combination of elements first row and first column give a content of each matrix cells [24]. Each cells can contain a possible solve of problem. But in fact, many combinations give impossible options or options that are not implemented under given restrictions. The cells that are have sense the material of collective discussion. The final selection is performed using expert evaluation techniques.

\subsection{The personality types selection}

The preparation of students to use creativity enhancement method one lecture session and one practical session were provide.

According to the method especially selected students performed determination techniques. The moderator of discussion should be with personality type ENTJ or ESTJ [21, 22]. For collective discussion the ENTJ, ENTP, ESTJ and INTJ personality types are recommended [22, 25, 26]. These types are arranged in the order in which they are best suited for this technique. For criticism the types sequences in order of their degree of preferable: ISTP, INTP, ISTJ, ESTJ [25, 27, 28]. For expert evaluation the same type can be used only at another sequences their degree of preferable. For technique of random associations the types ENTP and ENTJ should be added to discussion group [21, 26]. For technique of analogy a type INTJ should be used $[22,25]$.

\section{The results of the experiment}

The experiment was attended by students of SUNPU prospective teachers of mathematics. Every year, the subject studied two academic groups. The experiment was carried out during 2014-2020. Students were assigned to two or three project teams. The academic group was reorganized into a project team if the number of students was less than 15 or two project teams if the number of students was more than 15 . Thus, there were two or three project teams. The teams were of three types. The third project team were participants, who were doing methodical task without special preparatory training for this task. The members of the first project team took additional sessions to learn the creativity enhancement method. The participant of this team especially selected on the base of their personality type. The types, which corresponded with personality type to need a heuristic technique of method, were included in team. Members of the second project team are also studying the heuristic method. Students of the third project team didn't have additional classes. In total, sixteen project teams were created: a fifth team of the first type, three teams of the second type, and three teams of the third type (Table 1).

The total number of problems prepared by the teams is presented in Figure 2. The tournament was organized for project teams as part of the study of the discipline «Mathematics training methodology». IPT rules were used for the competition. If there were three teams, then each of the teams consistently acted as a speaker, opponent and reviewer. In the competition between the two teams, there were only speakers and opponents. The teams were tasked with developing a set of geometric problems, namely, a planimetry subsection. The topic of these problems set is established the same for all teams. This set of problems can be used in the school curricula. Specific requirements for this set are established: definite purpose of using, the arrangement of the problems in increasing order of difficulty and the availability of the alternate problems (with the same level of difficulty as well as methodical recommendations).

Table 1: Types of team per year

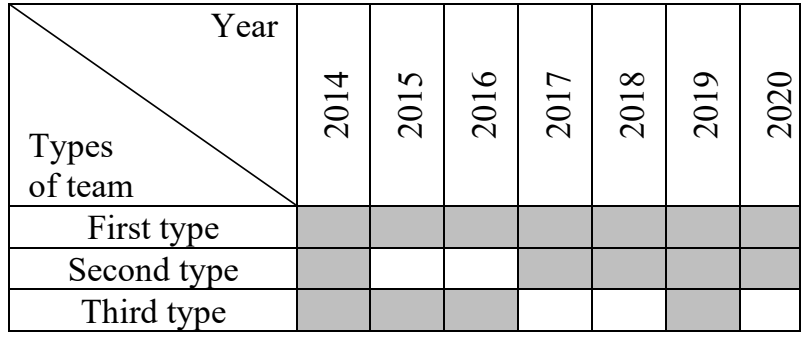

The work of teams of the first and second types was organized in accordance with the heuristic method algorithm. The collective discussion group included from 5 to 10 people, depending on the number of project team members. The ideas put forward by them were discussed by a group of critics of 3-5 people, together with some of discussion group participants. The final decision is made by an expert evaluation group of three people, one of whom is a moderator. Then the team was divided into two parts, one discussed the specific content of the rows, the second columns. Groups is performed this task using free association and analogy techniques. Based on the results of the discussion, a matrix was drawn up. Schemes of problems were depicted in the corresponding cells of the matrix. The discussion group is selected problems for further development. Then, the team, to increase productivity, split into parts and worked on selected problems. For each problem it was necessary to find several solutions and develop methodological recommendations. The expert evaluation group with high-achieving students selected problems that could be presented.

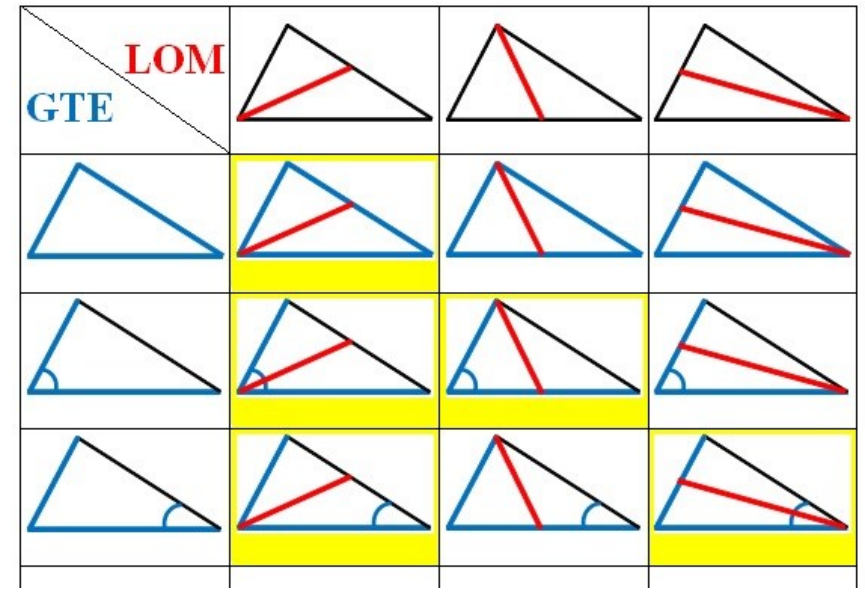

Figure 1: Example of a table with options for problems

An example of a fragment of one of the matrices obtained by the command of the second team type is presented in Figure 1. The 
elements that need to be found are marked in red. These are the medians drawn to the three sides of the triangle. The first row of the matrix is location options of medians (LOM). The first column contains the given triangle elements (GTE). Each cell of the second row corresponds to a triangle with all sides are given.

Of the three options for the location of the median, only one was chosen, since in all three cases the solution algorithm is the same. In the third row, there are triangles in which two sides and the angle between them are known. Two options are selected when the median is drawn from a known angle and when it is drawn from an unknown angle. In the fourth row, there are triangles in which two sides and angle are known but the angle is not located between them. Two variants are also chosen when the median is drawn from a known angle and when it is drawn from an unknown angle. Further, in the matrix considered triangles in which one side is known. These rows are not shown. For each of the triangles marked with a yellow background, the team developed several solutions with explanations, as well as recommendations for the teacher on how to apply these problems in the school curricula.

The total number of problems prepared by the teams is presented in Figure 2 and Table 2. The team reported the results, usually there were several speakers. Students preparing the problem presented it. The panel evaluated the team members who participated in the presentation individually. The members of the opponent's team who participated in the discussion were also individually assessed. The participants of the opposing team looked for inaccuracies in the solution and deficiencies in the explanation. They raised objections to methodological recommendations and to the possibility of using the problem in the school course. On the basis of the report and discussion, the panel evaluated each of a set of problems. Problems with more than 100 points were selected for use in the school course. The number of problems selected by the panel is shown in Figure 3 and Table 2 .

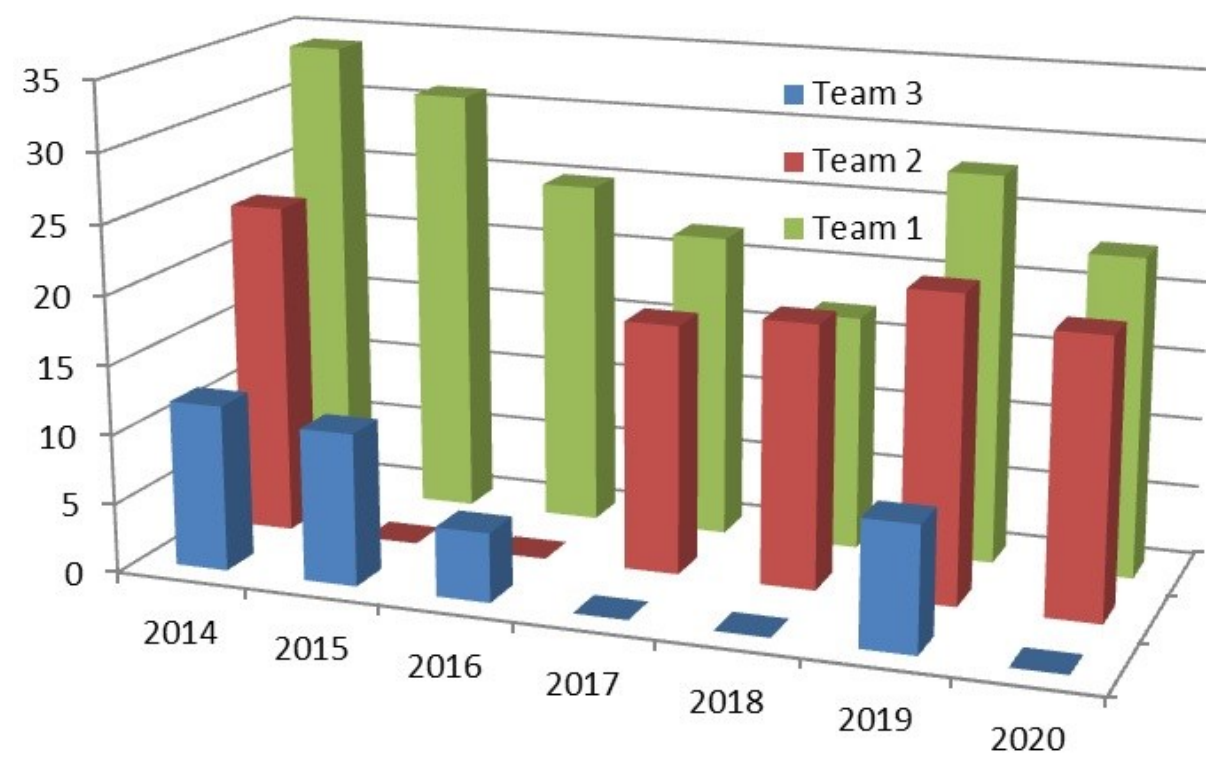

Figure 2: Total number of problems by year

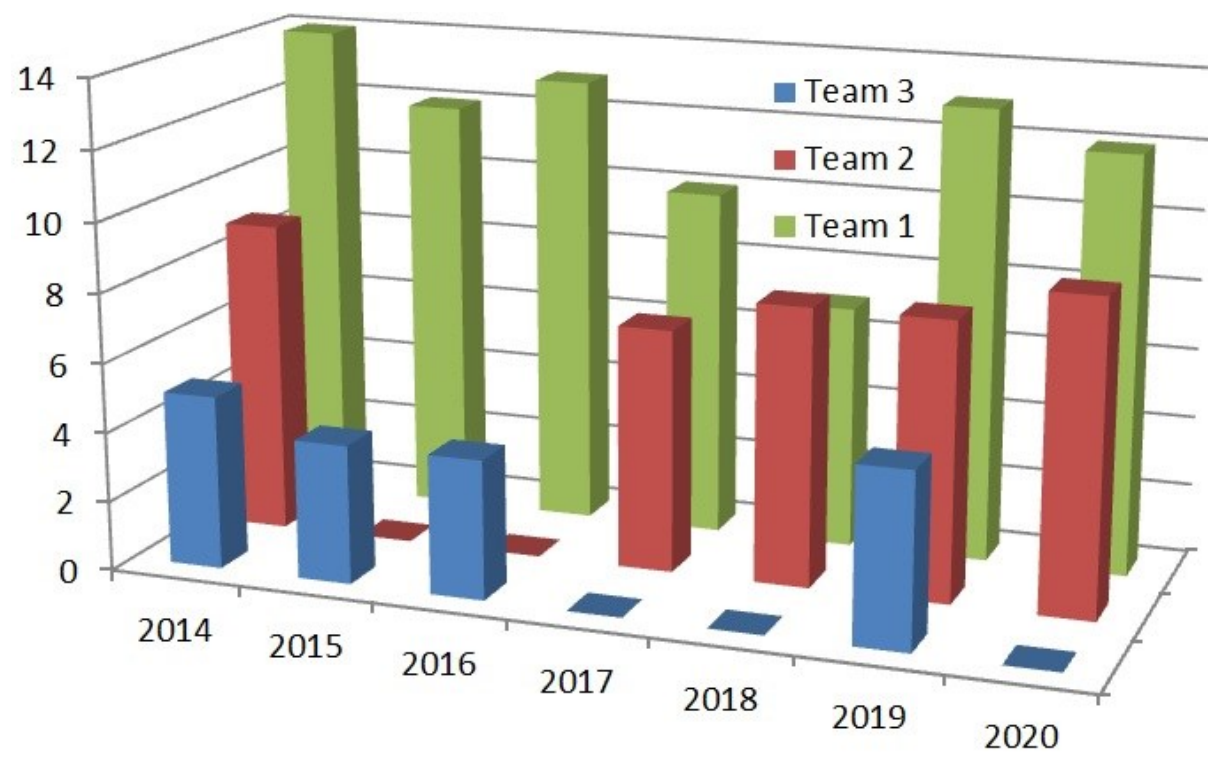

Figure 3: Selected number of problems per year 
Table 2: Team performance

\begin{tabular}{|c|c|c|c|c|c|c|}
\hline \multirow{2}{*}{$\begin{array}{r}\text { Team } \\
\text { Year }\end{array}$} & \multicolumn{2}{|c|}{ Team 1 } & \multicolumn{2}{c|}{ Team 2 } & \multicolumn{2}{c|}{ Team 3 } \\
\cline { 3 - 7 } & Total & $\begin{array}{c}\text { Se- } \\
\text { lected }\end{array}$ & Total & $\begin{array}{c}\text { Se- } \\
\text { lected }\end{array}$ & Total & $\begin{array}{c}\text { Se- } \\
\text { lected }\end{array}$ \\
\hline 2014 & 34 & 14 & 24 & 9 & 12 & 5 \\
\hline 2015 & 31 & 12 & - & - & 11 & 4 \\
\hline 2016 & 25 & 13 & - & - & 5 & 4 \\
\hline 2017 & 22 & 10 & 18 & 7 & - & - \\
\hline 2018 & 17 & 7 & 19 & 8 & - & - \\
\hline 2019 & 29 & 13 & 22 & 8 & 9 & 6 \\
\hline 2020 & 24 & 12 & 20 & 10 & - & - \\
\hline
\end{tabular}

The results of the student survey showed an increase in the interest of team's members of all types in the project method and the heuristic method. The students of the first type of team showed enthusiasm for defining their personality types and organizing the team work based on this data. As for the prospects for using the acquired skills in further work, everything is not so unequivocally. Most of the students of the first type team are not going to use the knowledge gained about personality types in their further work. Almost half of them are ready to use the heuristic method in the future, in contrast to participants from teams of the second type. The project method of work was assessed by the students of teams of three types as the most deserving of use in the work of a teacher (Table 3).

Table 3: Types of team per year

\begin{tabular}{|c|c|c|c|}
\hline Survey questions & 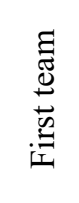 & 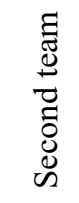 & 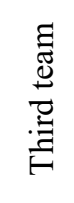 \\
\hline Do you like the project method? & $89 \%$ & $84 \%$ & $73 \%$ \\
\hline Do you like the heuristic method? & $77 \%$ & $69 \%$ & - \\
\hline $\begin{array}{l}\text { Do you like the distribution team role due } \\
\text { personality type? }\end{array}$ & $82 \%$ & - & - \\
\hline $\begin{array}{l}\text { Will you use the project method in your } \\
\text { future work? }\end{array}$ & $65 \%$ & $71 \%$ & $58 \%$ \\
\hline $\begin{array}{l}\text { Will you use the heuristic method in your } \\
\text { future work? }\end{array}$ & $44 \%$ & $24 \%$ & - \\
\hline $\begin{array}{l}\text { Will you use the distribution team role due } \\
\text { personality type in your future work? }\end{array}$ & $23 \%$ & - & - \\
\hline $\begin{array}{c}\text { Has interest in studying the discipline } \\
\text { increased due to innovations in the form } \\
\text { of education? }\end{array}$ & $81 \%$ & $73 \%$ & $67 \%$ \\
\hline
\end{tabular}

\section{Analysis of experiment result and discussion}

The performance of the second type team, which used the heuristic method, is higher than the performance of the third type team. Teams of the second type developed 24 problems. The average number of problems in a set is 8 . The third type team developed 13 problems. The average number of problems in a set is 4,3 . Thus, the results of the experiment confirmed the hypothesis $H_{a}$.

www.astesj.com
The application of the heuristic method requires special training. One lecture and one practical session are the minimum time to explain the essence of the method. It would be desirable to have more time for this. But there is a problem associated with the allocation of even this short time. If the heuristic method were used in teaching several disciplines, then there would be an opportunity for additional training. The method is quite complex, and several times the teams invented the contents of the matrix during brainstorming and heuristic techniques of random associations and analogies are not used. Heuristic techniques of random associations and analogies can be used to search for the contents of rows and columns. If one technique does not work, the other can be used additionally. It is promising to use the heuristic method in long-term projects carried out during a semester or longer.

The performance of the first type team, which was formed taking into account the personality types of students, is higher than the performance of the second type team and much higher than the performance of the third type team. The first type of team developed sets of 56 problems. The average number of problems in a set is 11,2. The experimental results confirmed the hypothesis of $H_{b}$. This means that the selection of performers for the execution of heuristic techniques was performed correctly.

It is very difficult to select the necessary personality types for the project teams, considering the level of knowledge, motivation and the personal interaction and relationships due to the small number of students learning a certain subject. For to form first type team in some cases it was necessary to include the students that had rare personality types ENTJ (moderator) ENTP (discussion group) from another academic group. This reduced the performance of teams of the second and third types. Experience has shown the academic achievements of the students can be more important than the exact matching of their personality types with their role in the creativity enhancement method. Sometimes we had to include the students from different academic groups into the project teams to strike a balance between the levels of their knowledge. The correct selection of team members of the first type allows students to understand the advantages of the method through a successful result. The project team included not only students with a personality type that is suitable for performers of heuristic techniques. Thus, it was necessary to find a model of participation for those who have a different personality type. Experience shows that the ENFP can act as a moderator, facilitating discussion through one's own imagination and enthusiasm. The personality type ENFJ can substitute INTJ in the discussion group because of their ability to generate the ideas. The personality type ENFJ can also fulfil the role of the teacher assistant when teaching creativity enhancement method. Having the big number of the representatives of personality types ISTJ, INTJ, INTP, ISTP, in the discussion group, it makes sense to give the students time to make the record of their ideas before the beginning of the discussion. A higher level of students' knowledge is created the prerequisites for the effective execution of the chosen role when working in a project team. However, this students, who did not have high grades earlier with the matching of their personality type with the appointed role surprisingly enough showed a better efficiency. For example, a student of personality type ISTJ, with an average level of academic achievement, working as a critic in a project team, enthusiastically is joined the work in detail analyzing the proposals of other team members. This 1134 
is allowed him to systematize and deepen his knowledge and skills appropriate way for him. The personality types of students, who show high results in the experiment, usually coincide with the typical personality types for STEM specialties: ISTJ, INTP, ESTJ, INTJ, ENTP, and ENTJ.

The survey showed that the members of the three types of teams were enthusiastic about the project method implemented in the form of competition. $82 \%$ of the total number of students liked the participation in the project. Students, who are going to use the project method in their profession - 64,7\%. Thus, hypothesis $H_{c}$ is confirmed.

The number of students in project teams is higher than recommended by the majority of research. This is due to the lack of teachers to conduct the research. Another problem of the project method was the organization of teamwork in such a way that all team members took an active part in it. We did not have this problem with the work of the first type of teams, unlike the second and third type teams. This serves as an indirect confirmation of the success of team interaction based on personal types. When using project method, there has always been the problem of assessing the personal contribution of team members and, accordingly, evaluating their academic achievements. Not all students presented solutions to problems and participated in the discussion. In the first type team, the students, in particular, the moderator, were involved in the assessment, which contributed to its objectivity and validity. The fact that students who solved the problem represent it is good for their self-realization, but it can be bad for the team score. From the point of view of higher score of the team, it is advisable to entrust the presentation of problems to students with high academic achievements.

\section{Conclusion}

The experiment was conducted in the form of a tournament, which made it possible to implement the PBL project and at the same time the role-playing project. The project had the final product - a set of geometry problems. Students studied the creativity enhancement method using the principle of "learning by doing". Thus, the project was comprehensive. Three types of project team took part at competition. Students of first and second project team are learned the heuristic method. Students of third project team haven't special training. It was found that the use of the project method in the form of a team competition aroused increased interest among students. It has been established also that the use of the heuristic method improves the performance of the project team. Members of first project team were selected according to their personality types. It was proven that the selection of students with certain personality types to the project team, the most suitable for the implementation of the heuristic techniques of the method, allowed increasing the performance of the project team. This confirms the correctness of the recommendations for the selection of personality types corresponding to a certain heuristic techniques. It is best to choose students with the ENTJ personality type for the role of moderator. It is recommended to choose personality types ENTP, ENTJ, INTJ for discussion and generation of ideas. The ISTP, INTP and ISTJ personality types should be used as criticisms. Several members of a collective discussion group must necessarily be at the group of critics. However, among the critics, there should be several members of the project team who did not participate in the discussion, for unbiased analysis of the proposed solutions. Academic achievement affects the performance of teams along with the personality types of students. This is important to consider when choosing a moderator and discussion group members. For this reason, the preferred ENTJ types can be replaced with ESTJ as the moderator, and ENTP can be replaced with INTP in the discussion group.

\section{Conflict of Interest}

The authors declare no conflict of interest.

\section{Acknowledgments:}

This work has been accomplished with financial support by the Grant No BG05M2OP001-1.002-0011 "MIRACle (Mechatronics, Innovation, Robotics, Automation, Clean technologies)", financed by the Science and Education for Smart Growth Operational Program (2014-2020) and co-financed by the European Union through the European structural and Investment funds.

\section{References}

[1] S. Ivanova, L. Dimitrov, V. Ivanov and G. Naleva, "An Experiment on the Joint use of the Heuristic and Project Methods at the University," in 2019 IEEE International Conference on High Technology for Sustainable Development (HiTech), 1-5, doi: 10.1109/HiTech48507.2019.9128248.

[2] R. Seidel, E. Godfrey, "Project and team based learning: An integrated approach to engineering education," In 4th ASEE/AaeE Global Colloquium on Engineering Education, №146, 2005.

[3] H. W. Reese, "The learning-by-doing principle. Behavioral development bulletin, " 17(1), 1-19, 2011. doi.org/10.1037/h0100597.

[4] J. Adderley, Project Methods in Higher Education, Research into Higher Education Monograph 24 London: Society for Research into Higher Education, 1975.

[5] A. Kolmos, E. De Graaff, X. Du, "Diversity of PBL-PBL learning principles and models," In Research on PBL practice in engineering education, 9-21, 2009, doi.org/10.1163/9789087909321_003.

[6] W.H. Kilpatrick, "The project method," Teachers college record, 19(4), 319335. 1918.

[7] N.K.Malhotra, A. Tashchian, A.K. Jam, "The project method approach: An integrated teaching tool in marketing research," Journal of Marketing Education, 11(2), 32-40, 1989, doi.org/10.1177/027347538901100206.

[8] J. E. Mills, D. F. Treagust, "Engineering education-Is problem-based or project-based learning the answer," Australasian journal of engineering education, 3(2), 2-16, 2003.

[9] A. Kolmos, "Reflections on project work and problem-based learning,: European journal of engineering education, 21(2), 141-148, 1996, doi.org/10.1080/03043799608923397.

[10] L. Helle, P. Tynjälä, E. Olkinuora, "Project-Based Learning in PostSecondary Education - Theory, Practice and Rubber Sling Shots," High Educ., 51, 287-314, 2006, https://doi.org/10.1007/s10734-004-6386-5.

[11] R. Harms, "Self-regulated learning, team learning and project performance in entrepreneurship education: Learning in a lean startup environment," Technological Forecasting and Social Change, Elsevier, 100, 21-28, 2015, doi: 10.1016/j.techfore.2015.02.007.

[12] Е.С. Полат, Новые педагогические и информационные технологии в системе образования. Академия. 2009.

[13] Т.И. Гречухина, А.В. Меренков, С.В. Куньщиков, И.Ю. Вороткова, А.В. Усачева, Самостоятельная работа студентов: виды, формы, критерии оценки, Екатеринбург: Издательство Уральского университет, 2016.

[14] А.Т. Ашеров, В.І. Шеховцова, “Проектная культура будущих инженеров-педагогов компьютерного профиля: сущность понятия,” Теорія і практика управління соціальними системами, 4, 7079, 2007.

[15] G. Kirkpatrick, "Online 'chat' facilities as pedagogic tools: a case study," Active Learning in Higher Education, 6(2), 145-159, 2005, doi.org/10.1177/1469787405054239. 
[16] S.A Barab, T.M. Duffy, "From practice fields to communities of practice," Theoretical foundations of learning environments, 25-55, 2000.

[17] О.П. Кальнік, “Індивідуалізація контролю навчальних досягнень студентів вищих навчальних закладів на основі використання соціонічних типів та установки на вид діяльності. Педагогіка та психологія." 53, 66-74, 2016.

[18] D. Prorak, T. Gottschalk, M. Pollastro, "Teaching method and psychological type in bibliographic instruction: effect on student learning and confidence," RQ, 33(4). 484-495. 1994.

[19] I. Talmi, O. Hazzan, R. Katz, "Intrinsic Motivation and 21st-Century Skills in an Undergraduate Engineering Project: The Formula Student Project," Higher Education Studies, 8(4), 46-58, 2018.

[20] V. Vanovskiy, "International Physicists' Tournament - the team competition in physics for university students," European Journal of Physics, 35(6), 064003, 2014. doi: 10.1088/0143-0807/35/6/064003.

[21] V. Ivanov, L. Dimitrov, S. Ivanova and O. Olefir, "Creativity enhancement method for STEM education," 2019 II International Conference on High Technology for Sustainable Development (HiTech), Sofia, Bulgaria, 1-5, 2019, doi: 10.1109/HiTech48507.2019.9128255.

[22] D. Keirsey, M. Bates, Please understand me. Del Mar, CA: Prometheus Nemesis, 1978.

[23] R.M. Capraro, M.M. Capraro, "Myers-Briggs Type Indicator score reliability across studies: A metaanalytic reliability generalization study," Educational and Psychological Measurement, 62(4), 590-602, 2002, doi.org/10.1177/0013164402062004004.

[24] V. Ivanov, G. Urum, S. Ivanova, G. Naleva, "Analysis of Matrix and Graph Models of Transmissions for Optimization Their Design." Eastern-European Journal of Enterprise Technologies, 4(1), 11-17, 2017, doi:10.15587/17294061.2017.107182

[25] M.H. McCaulley, "Myers-Briggs Type Indicator: A bridge between counseling and consulting". Consulting Psychology Journal: Practice and Research, 2000. https://dx.doi.org/10.1037/1061-4087.52.2.117]

[26] L. Moller, C. Soles, "Myers Briggs type preferences in distance learning education", International Journal of Educational Technology, 2(2), 2001.

[27] C.F. Yokomoto, R. Ware, "Applications of the Myers-Briggs Type Indicator in engineering and technology" Education--part II. Indiana UniversityPurdue University Indianapolis. Session, 2230, 4.88.1-4.88.10, 1999.

[28] D.W. Salter, N.J. Evans, D.S. Forney, "A longitudinal study of learning style preferences on the Myers-Briggs type indicator and learning style inventory", Journal of College Student Development, 47(2), 173-184, 2006. 